\title{
LITERASI INFORMASI DALAM TUGAS MINI RISET MAHASISWA BARU JURUSAN BIOLOGI PADA MATA KULIAH MORFOLOGI TUMBUHAN
}

\author{
Abdul Rasyid Fakhrun Gani ${ }^{12^{*}}$, Widya Arwita ${ }^{1}$, Silvana Syahraini ${ }^{1}$, Nur Kholijah Daulay ${ }^{3}$ \\ ${ }^{1}$ Pendidikan Biologi, FMIPA, Universitas Negeri Medan. \\ ${ }^{2}$ Mahasiswa Program Studi S2 Pendidikan Biologi, FMIPA, Universitas Negeri Malang. \\ ${ }^{3}$ Pendidikan Matematika, FMIPA, Universitas Negeri Medan. \\ *Korespondensi Author: rasyidabdul547@gmail.com
}

\section{INFO ARTIKEL}

\section{Riwayat artikel:}

Diterima 8 September 2020

Revisi 3 November 2020

Dipublikasikan 15 November 2020

Kata kunci:

Literasi Informasi, Mini Riset, Mofologi Tumbuhan

\begin{abstract}
ABSTRAK
Penelitian ini bertujuan untuk mengetahui literasi informasi mahasiswa pada tugas mini riset mata kuliah Morfologi Tumbuhan. Aspek yang akan diteliti adalah kemampuan mencari dan mengambil informasi, sumber informasi, dan kemampuan menggunakan informasi. Populasi pada penelitian ini adalah mahasiswa baru Jurusan Biologi Universitas Negeri Medan (Unimed) angkatan 2019 yang mengambil mata kuliah morfologi tumbuhan pada tahun akademik 2019/2020 yang berjumlah 100 orang, dan sampel diambil secara menyeluruh (total sampling). Penelitian ini termasuk kedalam penelitian kualitatif dengan teknik pengambilan data adalah dokumentasi portofolio tugas mini riset morfologi tumbuhan mahasiswa. Teknik analisis data dilakukan dengan cara reduksi data, penyajian data, dan penarikan kesimpulan dan verifikasi data. Hasil pada penelitian ini adalah mahasiswa sudah mampu mencari dan mengambil informasi secara efisien dan efektif. Sumber informasi yang digunakan mahasiswa adalah buku cetak, buku online, dan jurnal online. Mahasiswa juga sudah bisa mengevaluasi informasi yang diperolehnya akan tetapi tingkat plagiarisme mahasiswa tergolong tinggi. Kesimpulan yang dapat diambil adalah mahasiswa beru sudah memiliki kemampuan literasi informasi pada mata kuliah morfologi tumbuhan tetapi diperlukan latihan agar mahasiswa terhindar dari plagiarisme.
\end{abstract}

\section{ABSTRACT}

This study aims to determine the information literacy of students in the mini research assignment in the Plant Morphology subject. Aspects to be studied are the ability to find and retrieve information, sources of information, and the ability to use information. The population in this study were 100 new students of the Department of Biology at the State University of Medan (Unimed) who took plant morphology courses in the 2019/2020 academic year, and the sample was taken as a whole (total sampling). This research is a qualitative study. The data collection technique is the documentation of the student's miniature plant morphology research assignment. The data analysis technique was carried out by means of data reduction, data presentation, and drawing conclusions and data verification. The result of this research is that students are able to find and retrieve information efficiently and effectively. Sources of information used by students are printed books, online books, and online journals. Students are also able to evaluate the information, but the level of student plagiarism is high. The conclusion that can be drawn is that new students already have information literacy skills in the plant morphology course, but students have to practice to avoid the plagiarism.

Copyright (C 2019 Universitas Negeri Medan. Artikel Open Access dibawah

lisensi CC-BY-4.0 (https://creativecommons.org/licenses/by/4.0) 
How to Cite:

Gani, A.R.F., Arwita, W., Syahraini, S., \& Daulay, N.K. (2020). Literasi Informasi Dalam Tugas Mini Riset Mahasiswa Baru Jurusan Biologi Pada Mata Kuliah Morfologi Tumbuhan. Jurnal Pelita Pendidikan, 8(3), 174-180.

\section{PENDAHULUAN}

Literasi informasi merupakan kemampuan yang sangat penting di era revolusi industri 4.0 ini. Literasi informasi mencakup kegiatan untuk mengetahui informasi, mengambil informasi tersebut dan menggunakannya untuk menyelesaikan masalah yang dihadapi. Informasi menjadi pusat perhatian dalam penelitian literasi informasi (Schiffl, 2020). Dalam literasi informasi sangat dibutuhkan pemahaman akan sumber informasi dan bagaimana cara untuk mencari dan mengambil informasi tersebut. Menurut Pulungan (2019) literasi informasi sangat penting bagi kehidupan manusia karena memiliki banyak manfaat seperti membantu dalam mengambil keputusan, menemukan informasi secara efisien, membagi informasi, menambah dan memperdalam pengetahuan, mengevaluasi dan meningkatkan kemampuan berfikir analitis, serta melatih untuk menulis sebuah informasi. Shopova (2014) dalam penelitiannya membahas beberapa indikator literasi informasi, diantaranya adalah kemampuan mencari dan mengambil informasi, sumber informasi dan kemampuan menggunakan informasi.

Sumber informasi merupakan tempat informasi berasal. Dengan mengetahui sumbersumber informasi yang ada, pencarian informasi akan sangat mudah dilakukan. Sumber informasi dapat berasal dari mana saja dan dapat berkembang sesuai zamannya seperti perpustakaan, buku, majalah, jurnal, dan berbagai jenis informasi lainnya. Saat ini perpustakaan yang dianggap sebagai penyedia informasi sudah banyak yang menggunakan sistem digital untuk meningkatkan pelayanannya. Perpustakaanperpustakaan online sudah sangat mudah diakses dan tidak perlu datang langsung ke perpustakaan tersebut untuk memperoleh informasi. Pelayanan informasi tersebut terus dikembangkan untuk mempermudah kegiatan manusia, Andayani (2014) menyatakan bahwa perkembangan penerbitan elekronik yang jelas dan didukung oleh infrastruktur yang yang mendukung untuk mengakses informasi.

Mengakses informasi merupakan kegiatan untuk memperoleh informasi yang diinginkan dari sumbernya. Kegiatan ini membutuhkan keterampilan tertentu dalam pelaksanaannya. Saleh, dkk., (2017) Menyatakan bahwa mencari dan mengambil informasi adalah menangkap maksud isi informasi dan mengambilnya agar dapat dikelola. Setelah mendapatkan informasi yang dibutuhkan, diharuskan membaca isi dari sumber informasi tersebut secara kritis. Dari kumpulan informasi tersebut, pengambilan dan pengeloaan dengan baik sehingga informasi tersebut dapat kita gunakan dengan sebaikbaiknya. Iskandar (2016) berpendapat bahwa kemampuan seseorang menemukan informasi ketika memanfaatkan perpustakaan dan sumber informasi sebagai sarana untuk keberhasilan dalam literasi informasi.

Proses literasi informasi perlu dilakukan dalam setiap kegiatan, termasuk kedalam pembelajaran di kelas maupun penyelesaian tugas-tugasnya. Universitas Negeri Medan (Unimed) telah menerapkan tugas-tugas berbasis Kurikulum Kerangka Kualifikasi Nasional Indonesia (KKNI). Tugas-tugas tersebut dapat mengembangkan daya berfikir dan wawasan mahasiswanya untuk memenuhi empat aspek kebutuhan berdasarkan kurikulum KKNI yaitu sikap (attitude), bidang kemampuan kerja, pengetahuan, dan manajerial dan bertanggung jawab (Effiyanti, 2018). Dan salah satu tugas yang mengharuskan mahasiswa untuk memiliki banyak informasi untuk menjawab permasalahan pembelajaran adalah tugas mini riset yang diterapkan dalam semua mata kuliah.

Morfologi tumbuhan adalah salah satu mata kuliah di Jurusan Biologi Unimed yang wajib dipelajari bagi mahasiswa. Berdasarkan penelitian Gani dan Arwita $(2019$,$) pelaksanaan mata kuliah$ tersebut telah disusun dalam rencana perkuliahan semester (RPS). RPS tersebut telah mengatur rancangan pembelajaran, metode pembelajaran, penugasan, evaluasi beserta tanggal pelaksanaannya. Secara umum setiap proses pembelajarannya sudah berlangsung dengan baik. Mata kuliah ini juga sudah menerapkan tugastugas berbasis kurikulum KKNI, termasuk tugas mini riset yang dilakukan pada materi Morfologi bunga. Dan Mata kuliah morfologi tumbuhan ini diambil oleh mahasiswa prodi Biologi angkatan 2019 pada tahun akademik 2019/2020 yang termasuk kedalam mahasiswa semester awal.

Berdasarkan wawancara, belum diketahui sumber informasi dan kemampuan mahasiswa dalam mencari dan mengambil informasi berdasarkan analisis tugas mini riset secara mendalam pada mata kuliah morfologi tumbuhan. 
Oleh sebab itu dilakukannya penelitian ini untuk mengetahui kemampuan mencari dan mengambil informasi, sumber informasi dan kemampuan menggunakan informasi mahasiswa biologi pada mata kuliah morfologi tumbuhan. Penelitian ini juga bermanfaat sebagai landasan untuk mengembangkan pembelajaran morfologi tumbuhan di masa yang akan datang.

\section{METODE PENELITIAN}

Penelitian ini dilaksanakan di Universitas Negeri Medan yang beralamat di Jalan Willem Iskandar / Pasar V, Medan, Sumatera Utara, Indonesia. Subjek pada penelitian ini adalah mahasiswa Jurusan Biologi pada semester ganjil tahun 2019/2020 yang sedang mengambil mata kuliah morfologi tumbuhan berjumlah 100 orang mahasiswa.

Penelitian ini merupakan jenis penelitian kualitatif yang dilakukan dengan tiga tahap yaitu : 1) Tahap pra penelitian, dilakukan dengan merancang dan mempersiapkan keberlangsungan penelitian seperti survei lokasi, penyusunan dan validasi instrumen; 2) Tahapan penelitian, dilakukan dengan mengumpulkan dan menganalisis tugas mini riset mahasiswa pada mata kuliah morfologi tumbuhan; dan 3)Tahap pasca penelitian, dilakukan penyusunan laporan setelah data penelitian didapat. Teknik pengumpulan data dilakukan dengan penilaian dokumentasi portofolio tugas mini riset mahasiswa menggunakan lembar penilaian literasi informasi yang membahas aspek kemampuan mencari dan mengambil informasi, sumber informasi, dan kemampuan menggunakan informasi. Penilaian dilakukan dengan pemberian "ya" atau "tidak" pada kategori penilaian disetiap aspek. Teknik analisis data dilakukan dengan reduksi data, penyajian data, dan penarikan kesimpulan dan verifikasi data. Analisis tersebut dilakukan dengan persentasi hasil penilaian literasi informasi serta plagiarismenya.

\section{HASIL DAN PEMBAHASAN}

\section{Kemampuan Mencari dan Mengambil Informasi Mahasiswa}

Tugas mini riset dilakukan untuk menjawab permasalahan yang ada dengan penelitian dan penyusunan laporan. Untuk menyelesaikan laporan tersebut, mahasiswa perlu mencari dan mengambil informasi yang sesuai. Adapun cara mahasiswa untuk melakukan hal tersebut dijelaskan pada Tabel 1.

Tabel 1. Hasil penilaian kemampuan mencari dan mengambil informasi mahasiswa

\begin{tabular}{llcc}
\hline \multirow{2}{*}{ No } & \multicolumn{1}{c}{ Deskripsi } & \multicolumn{2}{c}{$\begin{array}{c}\text { Kegiatan mencari dan mengambil } \\
\text { informasi }\end{array}$} \\
\cline { 3 - 4 } & & $\begin{array}{c}\text { Tidak melakukan } \\
(\%)\end{array}$ \\
\hline 1 & $\begin{array}{l}\text { Akses informasi yang efektif dan efisien } \\
2\end{array}$ & $\begin{array}{l}\text { Penentuan berbagai jenis dan format sumber informasi } \\
\text { potensial (mis. Multimedia, database, audio / video, buku) }\end{array}$ & 19,23 \\
3 & Diferensiasi karakteristik utama dari sumber daya informasi & 100,00 & 80,93 \\
\hline
\end{tabular}

Mahasiswa sudah mampu dalam mencari dan mengambil informasi secara efisien dan efektif. Hal ini ditunjukkan dengan tepatnya informasi yang digunakan mahasiswa dalam menyusun tugasnya, seperti kesamaan topik informasi dan topik yang dibahas mahasiswa dalam sub-sub judulnya. Mahasiswa juga dapat mendiferensiasi informasi yang diperolehnya menjadi beberapa karakter, seperti membagi informasi ke dalam judul-judul tertentu di setiap bab dan membaginya lagi kedalam sub judul. Akan tetapi kegiatan pembagian karakter ini secara umum hanya dilakukan pada tinjauan teoritis atau bab ii. Mahasiswa juga belum mampu dalam menggunakan berbagai macam sumber informasi yang ada, rata-rata mahasiswa mengtutip bukubuku karangan dosen dan hanya sedikit mahasiswa yang mengutip sumber informasi terpercaya lainnya. Buku-buku yang biasa dikutip mahasiswa adalah buku penuntun praktikum dan buku morfologi tumbuhan yang sudah memiliki ISBN. Dan buku-buku tersebut dikutip mahasiswa karena berisi informasi yang dapat menjawab tugas-tugas yang ingin diselesaikannya. Hal ini terjadi karena mahasiswa sudah biasa dalam menggunakan sumber informasi tersebut, sebelum menjalankan tugas mini riset mahasiswa telah menyelesaikan tugas review journal, critical book, dan tugas rutin yang menuntut mahasiswa mencari informasi dari berbagai sumber.

Tuntutan pada tugas maupun perkuliahan yang mengharuskan mahasiswa untuk mengakses banyak informasi menyebabkan timbulnya kegiatan pencarian informasi seperti akses 
informasi, kepuasan akses informasi, identifikasi konsep, penentuan jenis informasi, strategi pencarian informasi diferensiasi karakteristik informasi, dan identifikasi jenis sumber informasi. Dalam kegiatan tersebut tentu saja mahasiswa memilih kegiatan yang mudah dan sering dilakukannya. Menurut Winoto (2017) dengan adanya kemudahan dalam mencari informasi para pengguna informasi lebih memilih mencari informasi dari mesin pencarian informasi yang mudah seperti internet. Dan kemudahan mencari informasi menimbulkan paradigma sebagai berikut: 1) kebutuhan informasi untuk mendukung tugas harian, 2) kebutuhan informasi terkini atau muktakhir, dan 3) kebutuhan informasi berkaitan dengan pengambilan keputusan. Subarjo (2017) berpendapat metode untuk menelusuri informasi ini haruslah dari berbagai sumber informasi yang terus berkembang sehingga dapat membantu untuk menemukan informasi yang dibutuhkan secara cepat, mudah dan relevan.

\section{Sumber Informasi yang Digunakan Mahasiswa}

Dalam mengambil sebuah informasi, mahasiswa harus menilai dan memilih sumber yang digunakannya. Adapun sumber yang digunakan mahasiswa pada tugas mini risetnya dijelaskan pada tabel 2

Mahasiswa hanya menggunakan sumber informasi cetak dan non cetak. Keseluruhan sumber media cetak yang digunakan adalah buku cetak sebesar 96\%. Sedangkan e-media yang digunakkan secara keseluruhan merupakan $e$ journal atau jurnal online yaitu sebesar $86 \%$. Mahasiswa tidak mencantumkan sumber gambar dari galeri foto online dan perpustakaan digital, padahal mahasiswa menggunakan sumber tersebut didalam tugasnya. Mahasiswa juga tidak mencantumkan sumber video online, rekaman audio, dan museum virtual karena tugas yang dianalisis merupakan tugas tertulis yang tidak memberikan bukti penggunaan sumber belajar audiovisual mahasiswa.

Mahasiswa hanya menggunakan buku cetak, buku non cetak (online dan ada yang dapat diunduh dalam bentuk pdf), dan jurnal online. Mahasiswa tidak mencantumkan sumber sumber gambar yang diperolehnya dan sumber belajar mahasiswa, sehingga tugas mini riset hanya dapat ini hanya dapat menggambarkan sumber informasi yang diolah kedalam tulisan mahasiwa. Berdasarkan penelusuran plagiarismenya, mahasiswa juga tidak mencantumkan perpustakaan digital yang menjadi sumber informasinya. Sebagian mahasiswa memilih menggunakan buku cetak yang ada di perpustakaan sebagai sumber informasinya. Banyak mahasiswa yang memilih menggunakan sumber online yang berisi jurnal dan buku yang dapat di unduh. Selain karena mudahnya mengakses sumber informasi secara digital maupun online, mahasiswa memang selayaknya mampu menggunakan teknologi dengan cermat di era globalisasi ini (Gani dan Arwita, 2020). Era globalisasi ini menentukan metode penggunaan sumber informasi mahasiswa. Masitoh (2018) berpendapat seiring dengan perkembangan teknologi informasi dan komunikasi yang sangat pesat tersebut, saat ini sudah bermunculan istilah e-learning, online learning, web based training, online courses, web based education dll. Selain itu, sudah banyak lembaga pendidikan yang memanfaatkan sistem e-learning dalam pembelajaran untuk meningkatkan keefektifan dan fleksibilitas pembelajaran tersebut. Dengan menggunakan teknologi informasi, kebutuhan pembelajaran mahasiswa juga telah terpenuhi sehingga mahasiswa cenderung menggunakannya. Hal ini sependapat dengan pernyataan Herlina, dkk., (2015) yang menyatakan bahwa setiap orang membutuhkan informasi karena tuntutan kehidupan, penunjang dan pemenuhan segala kegiatannya.

\section{Kemampuan Menggunakan Informasi}

Menggunakan informasi sangat penting dalam menjawab setiap permasalahan dalam tugas mini riset. Adapun dalam mini riset mahasiswa. Mahasiswa perlu mendapatkan banyak informasi sebagai acuan dan pembanding dalam penelitiannya. Adapun kemampuan mahasiswa dalam menggunakan informasi dijelaskan pada tabel 3.

Tabel 2. Sumber yang digunakan mahasiswa dalam tugas mini risetnya

\begin{tabular}{llcc}
\hline No & Deskripsi & $\begin{array}{c}\text { Penggunaan } \\
\text { sumber (\%) }\end{array}$ & $\begin{array}{c}\text { Tidak } \\
\text { menggunakan (\%) }\end{array}$ \\
\hline 1 & Media cetak - koran, majalah, buku, ensiklopedia dan jurnal. & 96,00 & 4,00 \\
2 & E-media - surat kabar, majalah, buku, ensiklopedia dan jurnal. & 86,00 & 14,00 \\
\hline
\end{tabular}


Tabel 3. Kemampuan penggunaan informasi mahasiswa

\begin{tabular}{|c|c|c|c|}
\hline \multirow[b]{2}{*}{ No } & \multirow[b]{2}{*}{ Deskripsi } & \multicolumn{2}{|c|}{ Kegiatan penggunaan informasi } \\
\hline & & $\begin{array}{l}\text { Melakukan } \\
\text { (\%) }\end{array}$ & $\begin{array}{l}\text { Tidak melakukan } \\
(\%)\end{array}$ \\
\hline 1 & Menganalisis dan mensintesis informasi & 37,11 & 62,89 \\
\hline 2 & Interpretasi dan penyajian informasi & 9,28 & 90,72 \\
\hline 3 & Evaluasi kritis terhadap informasi & 51,55 & 48,45 \\
\hline 4 & $\begin{array}{l}\text { Evaluasi kritis terhadap sumber daya cetak dan online } \\
\text { berdasarkan kriteria tertentu }\end{array}$ & 56,70 & 43,30 \\
\hline 5 & $\begin{array}{l}\text { Memahami hak cipta dan mengikuti undang-undang, peraturan, } \\
\text { etika yang terkait dengan akses dan penggunaan sumber daya } \\
\text { informasi }\end{array}$ & 1,00 & 99,00 \\
\hline
\end{tabular}

Mahasiswa sudah menggunakan informasi yang untuk menjawab permasalahan yang ada pada tulisannya. Sebagian besar informasi dari sumber bacaan yang digunakan juga hanya terdapat pada bab ii atau tinjauan pustaka tetapi tidak ada kutipan pada bab yang lainnya, sehingga mahasiswa belum bisa menyajikan informasi dengan baik. Mahasiswa sudah bisa mengevaluasi informasi dan sumbernya dengan baik tetapi kurang memperhatikan kemutakhiran isi maupun sumber yang diperoleh. Mahasiswa juga belum dapat memverifikasi informasi yang diperolehnya, hal ini ditunjukkan dengan tidak adanya mahasiswa yang membandikan dua atau lebih informasi yang membahas topik permasalahan yang sama.

Mahasiswa sudah bisa melakukan kegiatan evaluasi informasi dan sumbernya. Hal ini karena sumber informasi yang digunakan mahasiswa banyak yang termasuk sumber informasi yang terpercaya. Tetapi tidak ada mahasiswa yang melakukan verifikasi keaslian dan keandalan sumber informasi dengan membandingkan informasi maupun data dari berbagai sumber. Padahal informasi harus digunakan untuk memenuhi kondisi atau syarat yang sesuai dengan nilai informasi tersebut, sehingga informasi sangat perlu untuk diolah (Suwahyono, 1995).

Dalam penggunaan informasi, mahasiswa kurang mampu dalam menganalisis dan menyajikan informasi. Analisis informasi mahasiswa hanya dalam pengelompokan informasi dalam sub-sub judul tinjauan teoritisnya, seharusnya kegiatan menganalisis informasi dilakukan dalam setiap penyajian informasi dengan berbagai metode sehingga diperlukan kreatifitas dan pengetahuan yang tinggi (Pulungan, 2019). Sedangkan dalam menyajikan informasi, mahasiswa belum mampu menjadikan informasi yang diperolehnya untuk mendukung data yang dimilikinya, seperti tidak membandingkan hasil rumus bunga yang diperolehnya (empirik) dan rumus bunga yang ada pada teori (teoretik). Mahasiswa juga belum mampu dalam membandingkan beberapa informasi yang diperoleh dan memberikan argumennya untuk menghasilkan informasi yang baik. Sehingga mahasiswa harus dibiasakan untuk dapat menganalisis suata masalah berdasarkan fakta dan data (Rezeqi dkk., 2020).

Secara umum mahasiswa belum memahami hak cipta dan undang-undangnya dengan baik, hal ini ditunjukkan dari plagiarismenya. Hanya $1 \%$ mahasiswa yang memiliki nilai plagiarisme ratarata 4,8\%. Adapun analisis plagiarisme mahasiswa disetiap bab laporan mini risetnya dijelaskan pada gambar 1. 


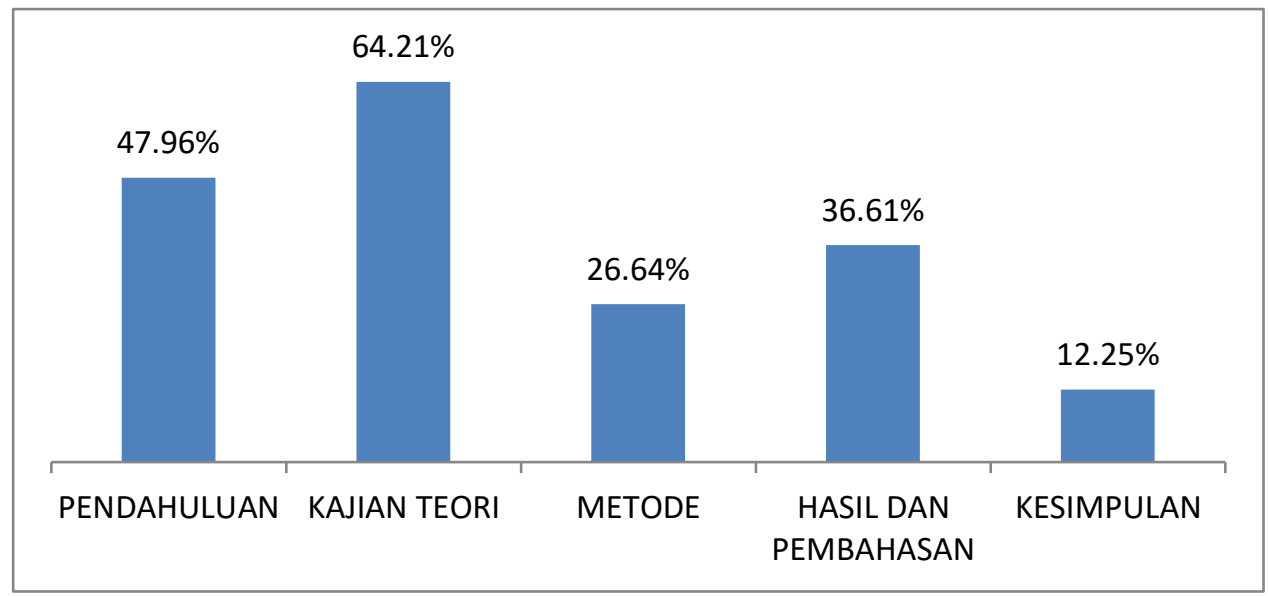

Gambar 1. Grafik tingkat plagiarisme mahasiswa disetiap bab

Plagiarisme mahasiswa dalam menulis tugas mini iriset ini termasuk dalam kategori tinggi. Mahasiswa banyak melakukan kegiatan plagiarisme dalam kegiatan mengutip kata atau kalimat orang lain tanpa menggunakan tanda kutip atau tanpa menyebutkan identitas sumbernya, menggunakan gagasan atau pandangan maupun teori orang lain tanpa menyebutkan identitas sumbernya (Sukaesih, 2018). Padahal Tingkat plagiarisme yang diperbolehkan adalah sekitar $10 \%$ dalam setiap penulisan pendahuluan dan metode serta $5 \%$ pada bagian lainnya (Moskovitz, 2017). Akan tetapi kegiatan plagiarisme sangat lazim dilakukan oleh mahasiswa dalam menyelesaikan tugasnya. Mahasiswa belum sepenuhnya menyadari bahwa mengutip suatu sumber tertentu tanpa mengolah atau memparafrasekan isinya dapat diindikasikan sebagai perilaku plagiarisme sekalipun penulis mencantumkan sumber tersebut. Berdasarkan penelitian Nimasari dan Gestanti (2017), mengutip tanpa mencantumkan sumber rujukan merupakan plagiarisme yang paling sering terjadi dikalangan mahasiswa, mahasiswa belum sepenuhnya mengutip dari sumber tertentu dengan mengolah atau memparafrasekan isinya. Rata-rata mahasiswa mengetik keseluruhan isi sumber yang ada di buku pegangannya, atau mahasiswa langsung copy-paste tugas yang ada di internet sehingga mahasiswa memiliki plagiarisme yang tinggi.

Kemampuan menggunakan informasi yang belum maksimal merupakan hal yang sangat wajar terjadi bagi mahasiswa yang masih semester satu untuk belajar menulis. Mahasiswa baru masih dalam proses adaptasi dengan lingkungan belajar yang ada di kampus. Mitasari dan Istikomayanti (2017) berpendapat lingkungan di perguruan tinggi sangatlah berbeda jauh jika dibandingkan dengan kehidupan sekolah. Wijanarko dan Syafiq (2013) berpendapat bahwa mahasiswa baru kesulitan dalam beradaptasi dengan lingkungan yang baru disebabkan oleh perbedaan bahasa, nilai, dan kebiasaan, di luar persoalan iklim geografis. Sehingga mahasiswa baru harus aktif mencari informasi terkait dengan kegiatan awal perkuliahan dan menjalankan kegiatan pembelajaran dengan sistem yang berbeda, apalagi ini baru pertama kalinya mahasiswa menjalankan tugas Mini Riset. Oleh sebab itu mahasiswa perlu perbaikan dan latihan untuk menulis agar meningkatkan kemampuan literasi informasi dan terhindar dari plagiarisme.

\section{KESIMPULAN}

Mahasiswa sudah mampu mencari dan mengambil informasi secara efisien dan efektif. Rata-rata sumber informasi yang digunakan mahasiswa adalah buku cetak, buku online, dan jurnal online. Dalam kegiatan penggunaan informasi, mahasiswa sudah bisa mengevaluasi informasi yang diperolehnya akan tetapi tingkat plagiarisme mahasiswa tergolong tinggi. Diperlukan perbaikan dan latihan agar mahasiswa terhindar dari plagiarisme saat menulis.

\section{UCAPAN TERIMA KASIH}

Terima Kasih diucapkan kepada LPPM Universitas Negeri Medan yang telah memberikan dana hibah dalam program penelitian Student Grant.

\section{DAFTAR PUSTAKA}

Andayani, Ulpah. (2014). Managemen SumberSumber Informatika Elektronik (EResources) di Perpustakaan Akademik. Almaktabah. Vol. 13(1), 8-19. 
Effiyanti, T., Pratiwi, DE., dan Dalimunthe, MB. (2018). Pengembangan Perangkat Pembelajaran Berorientasi KKNI Pada Mata Kuliah Ekonomi Syariah. Niagawan. Vol. 7 No 1, 44-49.

Gani, A.R.F., \& Arwita, W. (2020). Kecenderungan Literasi Informasi Mahasiswa Baru Pada Mata Kuliah Morfologi Tumbuhan. Jurnal Pelita Pendidikan, 8(2), 145-150.

Gani, ARF., dan Arwita, W. (2019). Profil Pembelajaran Mata Kuliah Morfologi Tumbuhan Untuk Mahasiswa Calon Guru Biologi. Makalah disajikan dalam Fourth Postgraduate Bioexpo, Seminar Nasional V. Workshop Biologi dan Pembelajarannya, 4 Oktober 2019.

Herlina. Suriana, S. dan Misroni. (2015). Perilaku Pencarian Informasi Mahasiswa Program Doktoral Universitas Islam Negeri Raden Fatah Dalam Penyusunan Disertasi. Tamaddun. Vol. XIV, No. 2.

Iskandar. (2016). Literasi Informasi: Perspektif Pustakawan. Iskandar / JUPITER. Volume XV No.1, 10-15.

Masitoh, S. (2018) Blended Learning Berwawasan Literasi Digital Suatu Upaya Meningkatkan Kualitas Pembelajaran dan Membangun Generasi Emas 2045. Proceedings of The ICECRS. Vol. 1(3), 1334.

Mitasari, Z. dan Istikomayanti, Y. (2017). Studi Pola Penyesuaian Diri Mahasiswa Luar Jawa Di Universitas Tribhuwana Tunggadewi Malang. Seminar Nasional dan Gelar Produk, 796-803.

Moskovitz, C. (2017). Text recycling in health sciences research literature: A rhetorical perspective. Research Integrity and Peer Review, Vol 2(1), 1-7. doi: 10.1186/s41073-017-0025-z.

Nimasari, E.P., dan Gestanti, R.A. (2017). Persepsi Mahasiswa Terhadap Plagiat. Premiere Educandum. Vol. 7(2), 115-123.

Pulungan, A.S.S. (2019). Literasi Informasi dan Manajemen Data. Surabaya: Pustaka Media Guru.

Rezeqi S., Brata, W.W.W., Handayani, D., Gani, ARF. (2020). Analisis Kebutuhan Bahan Ajar Taksonomi Organisme Tingkat Rendah Terhadap Capaian Pembelajaran Berbasis KKNI. Jurnal Pelita Pendidikan, 8(2), 126-133.

Saleh, A.R., Sujana, J.G., Ratnaningsih, Elvina, I. (2017). Literasi Informasi Untuk Mahasiswa IPB. Bogor: Institut Pertanian Bogor.
Schiffl, I. (2020). How Information Literate Are Junior and Senior Class Biology Students? Research in Science Education, 50(2), 773-789.

Shopova, T. (2014). Digital Literacy Of Students And Its Improvement At The University, ERIES Journal. Vol. 7 (2), 26-32.

Subarjo, AH. (2017). Perkembangan Teknologi Dan Pentingnya Literasi Informasi Untuk Mendukung Ketahanan Nasional. Jurnal Ilmiah Bidang Teknologi. Vol. 9(2), 1-8.

Sukaesih. (2018). Permasalahan Plaiarisme Pada Penelitian Kualitatif di Indonesia. Jurnal Politikom Indonesiana. Vol. 3(1), 210218.

Suwahyono, N. (1995). Pengelolaan Informasi: Suatu Pandangan Umum. BACA, Vol. XX, (1-2), 8-12.

Wijanarko, E. dan Syafiq, M. (2013). Studi Fenomenologi Pengalaman Penyesuaian Diri Mahasiswa Papua Di Surabaya. Jurnal Psikologi: Teori \& Terapan, Vol. 3, No. 2, 79-92.

Winoto, Y. (2017). Pemafaatan Sumber Informasi Jurnal Dan Buku Elektronik Di Perpustakaan Universitas Padjadjaran. Jurnal Edulib. Vol. 7(2), 74-81. 